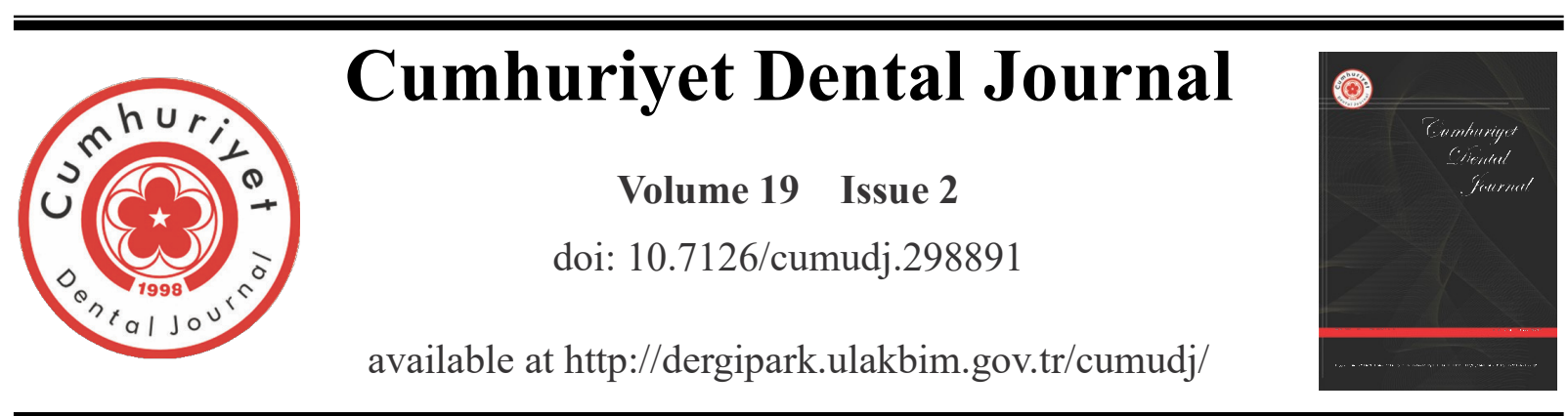

RESEARCH ARTICLE

\title{
The Effects of Allograft Combined with Ozone Therapy on Regeneration of Calvarial Defects in Rats
}

\author{
Hülya TOKER ${ }^{1}$, Hakan ÖZDEMIR ${ }^{2}$, Turan Emre KUZU ${ }^{3}$, Hatice ÖZER ${ }^{4}$ \\ ${ }^{1}$ Department of Periodontology, Faculty of Dentistry, Cumhuriyet University, Sivas, Turkey \\ ${ }^{2}$ Department of Periodontology, Faculty of Dentistry, Osmangazi University, Eskişehir, Turkey \\ ${ }^{3}$ Department of Periodontology Oral and Dental Health Center, Sivas, Turkey \\ ${ }^{4}$ Department of Patology, Faculty of Medicine, Cumhuriyet University, Sivas, Turkey
}

\section{A R T I C L E I N F O}

Article history:

Received 15.11.2015

Accepted 10.08.2016

\section{Keywords:}

Bone healing, allograft, ozone therapy, calvarial defect .

\section{A B S T R A C T}

Objective: Ozone accelerates wound healing and increases oxygen supply. The purpose of this study was to investigate the effect of ozone therapy combined with bone allograft on bone regeneration in rats with calvarial defects, histomorphometrically and histopathologically.

Material-Method: Twenty four male Wistar rats were used in this study. A $5 \mathrm{~mm}$ diameter critical-size defects were created in all rats using a trephine bur. The rats were divided into 4 groups; empty defect (control) $(n=6)$, ozone application into the control defect (control+ ozone) group $(n=6)$, defect filled with allograft (Allograft) group $(n=6)$, ozone combined with allograft application (allograft + ozone) group $(n=6)$. Gaseous ozone administered at $80 \%$ density for 14 days. The animals were euthanized at 8 -week. Total bone area was measured histomorphometrically and osteoclast and osteoblast number were analyzed histopathologically.

Results: The osteoblast numbers increased in allograft + ozone group compared to the allograft group $(\mathrm{p}<0.05)$. The control defects showed significantly less new bone formation than those of the allograft groups at 8 weeks $(\mathrm{p}<0.05)$. Total bone area was significantly higher in allograft+ozone group than those of the allograft group $(\mathrm{p}<0.05)$.

Conclusions: Within the limitations of this study, we suggested that allograft+ozone combination increased osteoblast number and new bone area. However, further studies are needed to investigate the mechanisms of action of ozone on bone regeneration.

Keywords: Bone healing, allograft, ozone therapy, calvarial defect. 


\section{INTRODUCTION}

The purpose of bone augmentation procedure is the formation of new bone after the healing in the area which was augmented. ${ }^{1}$ There are several grafts materials used for regeneration the autogenous grafts are considered the "gold standart" due to their osteogenic, osteoinductive and osteoconductive features. Although potential favorable properties of autogenous bone grafts, a tendency toward unpredictable resorption and morbidity at the donor site represents disadvantages of this grafts. ${ }^{2}$

Allograft is a tissue transferred from a donor to a recipient of the same species but of nonidentical genetic composition. ${ }^{3}$ Allografts are used freeze-dried demineralized bone allograft (FDBA) and demineralized freeze-dried bone allograft form known as (DFDBA). ${ }^{4}$

FDBA provides an osteoconductive effect to bone regeneration while DFDBA is to allow an osteoconductive surface while maintaining the additional benefit of its functioning as a source for the osteoinductive factors ${ }^{5}$ and its these features can be achieved by using structural bone morphogenetic proteins (BMP) such as BMP-2, 4, 7, its own structure. ${ }^{6}$ In a study reported that the combination of DFDBA and platelet rich plasma accelerated bone regeneration in dog mandible. ${ }^{7}$

When DFDBA is transplanted into bone with good vascularity, it permits the mesenchymal cells to migrate to the area consequently increase the osteogenesis. These events are induced by the following functions of the BMP; (1) mitogenic effects on undifferentiated mesenchymal cells and osteoblast precursors; (2) Stimulation of the osteoblast phenotype (increasing the alkaline phosphatase activity in the bone cells); (3) its functioning as chemo-attractant for mesenchymal cells, monocytes and Type 4 collagens that serve as cellular adhesion proteins. ${ }^{8}$ Studies suggested that during the preparation of allograft, the mechanical strength of the graft decreases in 50\%. ${ }^{9}, 10$ Furthermore, in the previous studies that were conducted on DFDBA, it was indicated that the regeneration has not occurred a certain because the osteoinductive proteins were not preserved at sufficient level during the sterilization and therefore there were no clinical estimates on this issue. ${ }^{11-13}$

Ozone is normally present as a gas made of three atoms of oxygen with a cyclic structure, a gaseous or aqueous form. ${ }^{14}$ The therapeutic effect of ozone is not only limited to the cell wall; therapeutic mechanisms is also related to bactericidal, virucidal and fungicidal action as well as having. Also, systemic hemostatic repair properties (enhancing the oxygen carrying capacity of the blood; optimization of pro- and anti-oxidative processes; regulating the microcirculation and peripheral blood circulation; dosedependent effect on blood clotting; activation of the production of the biologically active factors), immunomodulating effect, analgesic effect, and detoxifying effect. ${ }^{15}$

There are a few study investigating the effects of ozone on bone regeneration in literature. Furthermore, the previous our study demonstrated that graft regeneration increased significantly when ozone therapy in conjunction with autogenous grafts in the rat calvarial defects. ${ }^{16}$ However, the influence of ozone therapy on allograft healing has not been studied previously. Therefore, the aim of the present study was 
to examine the currency of this hypothesis in a critical size defect model experimentally created in rat calvaria and analyze the bone formation when ozone therapy in together with allograft

\section{MATERIAL-METHOD}

Twenty-four male Wistar rats were used in this study. The rats were 12-14-week old and were 210-220 grams. Rats were kept in individual plastic cages in an experimental animal room (21-C, 55\%-70\% humidity, 1 atm pressure, with a 12-hour day/night cycle). The animals were fed a standard laboratory pellet diet, and drinking water was available ad libitum during the experiment protocole. The approval for this study was received from the Local Ethical Committe for Animal Experiments at Cumhuriyet University.

\section{Surgical procedure}

Animals were anesthetized
preoperatively with an intramuscular injection of ketamine hydrochloride (40 $\mathrm{mg} / \mathrm{kg}$ body weight, $10 \% \mathrm{Ketasol}$; Richter Pharma AG, Wels, Austria). The surgical site was shaved and disinfected. An incision was made in the scalp in the sagittal plane longitudunally the cranium, allowing reflection of a full-thickness flap in a posterior direction. A $5 \mathrm{~mm}$ diameter critical size defect was made on the right side of the parietal bone with a trephine bur (MIS Implant Tech, Shlomi, Israel) used in a low-speed handpiece under continuous irrigation with sterile saline attention was paid not to perforate the underlying dura mater and not to involve the sagittal suture. (Figure-1.A)

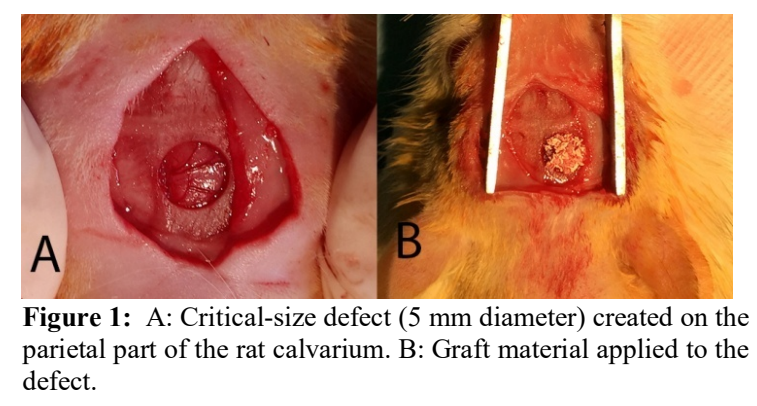

Animals were randomly divided into four groups as follows:

1- Empty defect (control) group ( $\mathrm{n}=6$ )

2- Ozone application into the empty defect (control+ozone) group $(\mathrm{n}=6)$

3- Allograft group $(n=6)$

4- Ozone Combined with Allograft application (allograft+ozone) $(n=6)$.

After preparing the recipient site, allograft $(0,5-1 \mathrm{~mm}$ particle size, cortical bone) (Maxeus dental, Ohio, ABD) was implanted into the bone defect (Figure1.B). The soft tissues were then sutured to achieve primary closure (4-0 catgut; Dogsan Sanayi, Istanbul, Turkey). To prevent postoperative infection, ceftriaxone (Roche, Basel, Switzerland) was given to the animals as intramuscular injections for 3 days $(30 \mathrm{mg} / \mathrm{kg}$ ). They were also given an intramuscular analgesic, $4 \mathrm{mg} / \mathrm{kg}$ carprofen (Pfizer, New York, NY, USA), every $24 \mathrm{~h}$ for $3 \mathrm{~d}$, starting immediately after the operation .

Ozone therapy was performed using an ozone generator (Biozonix, Munich, Germany). It was applied 60 s, $80 \%$ oxygen $(2100 \mathrm{ppm})$ every day for 14 days.

\section{Histologic evaluation}

At the end of the 8 week follow-up, animals were killed overdose of 200 $\mathrm{mg} / \mathrm{kg}$, iv, pentobarbital (Abbott Diagnostic Division, Abbott Park, IL, USA). The area of the original surgical defect and the surrounding tissues were removed en bloc. The blocks were fixed in 
$10 \%$ neutral formalin, rinsed with water and then demineralized in $10 \%$ formic acid. After decalcification, each specimen was divided longitudinally into two blocks in sagittal direction and embedded in paraffin. Serial sections ( $5 \mu \mathrm{m}$ thick) were cut in a longitudinal direction, beginning at the center of the original surgical defect. The sections were stained with hematoxylin and eosin for analysis under light microscopy (Nikon, Eclipse 80i, Tokyo, Japan). Histological analysis was performed by a single examiner who was also blinded to the identity of samples. To measure bone formation, the number of osteoblasts was counted in all defect area.

\section{Histomorphometric evaluation}

The images of the histologic sections in all groups were captured by a digital camera connected to a light microscope with an original magnification (X 4). The digital images were saved on a computer. The Clemex Vision-Lite 5.0 software (Clemex Technologies, Quebec, Canada) was used for used for total bone area $\left(\mathrm{mm}^{2}\right)$ as the histomorphometric analysis.

\section{Statistical analyses}

All statistical analyses were performed using a commercial computer program (SPSS system version 22; SPSS Inc., Chicago, IL, USA). The datas were subjected to statistical analysis with the Mann-Whitney U-test following the Kruskal-Wallis test (intergroup comparison). Differences of $\mathrm{p}<0.05$ were considered significant.

\section{RESULTS}

All rats survived to the end of the study, and no postoperative complications were noticed such as inflammatory tissue responses, exposure of graft material, or allergic reaction.
Histological sections were evaluated with a light microscope. In the control group, the defects generally were filled by thin fibrous connective tissue and the edges of defects were observed as thickening of the cortex. Also, it was observed that the number of the osteoclasts were lower in both control groups compared with the other groups $(\mathrm{p}<0.05)$. In comparisons among the groups, it was observed that there were no significant differences in osteoclast numbers between the allograft and allograft+ozone groups at 8 th week $(\mathrm{p}>0.05)$.

The osteoblast numbers were not significantly different between the control and control+ozone groups at 8 th week. However, numbers of osteoblast in allograft+ozone group were found statistically higher than those of the other groups ( $\mathrm{p}<0.05)$ (Figure-2).

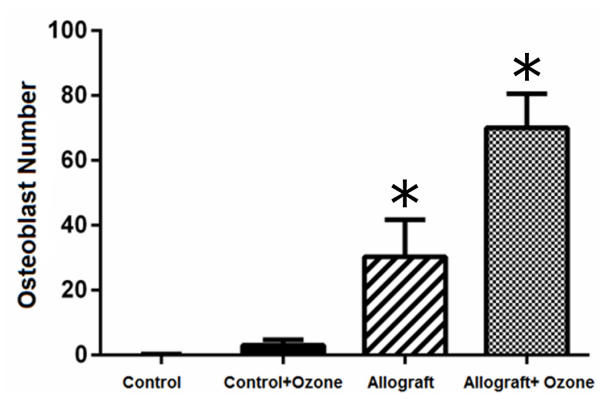

Figure 2: Osteoblast numbers for the study groups. ${ }^{*} \mathrm{p}<0.05$ vs. the other groups

New bone area measurements were statistically analyzed among the groups at 8th week. It was observed that the allograft+ozone group showed a significant increase in total bone area compared to other groups $(p<0.05)$ (Figure-3), while no statistical significance were observed between control and control+ozone group $(p>0.05) \quad$ (Figure-4). Also, new bone formation were observed less in the control and control+ozone groups. 


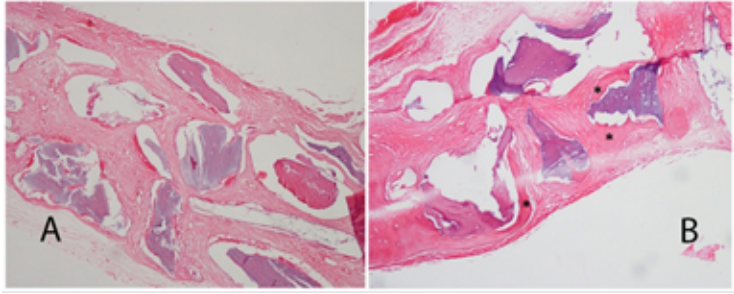

Figure 3: Histological sections in the allograft (A) and allograft+ozone (B) group, $\left(^{*}\right)$ indicates newly formed bone. (hematoxylin and eosin stain, original magnification $\mathrm{x} 100$ ).

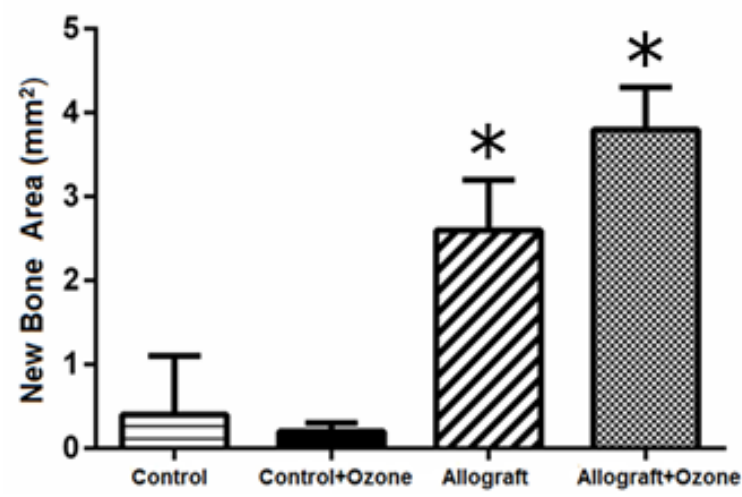

Figure 4. New bone area for all groups. ${ }^{*} \mathrm{p}<0.05$ vs. the other groups.

\section{DISCUSSION}

In this study, the issue of whether there is a contribution of the ozone gas and allograft material to new bone regeneration in critical defects in rat calvaria was determined. The rat calvarial defect model was preferred for this purpose. Because; (i) surgical procedures on the rat calvarial bone are relatively simple to perform; (ii) observations can be focused on the healing process of the bone, as there are no major nerves or blood vessels around the rat calvaria; (iii) the calvarial defect model has many similarities to the maxillofacial region, as anatomically the calvaria consists of two cortical plates with a region of intervening cancellous bone similar to the mandible; (iv) preparation of tissue specimens is easy; and (v) spontaneous healing would not occur at the control defect (critical size defect). ${ }^{17-19}$ Therefore, 5-mm diameter, spontaneously nonhealing, critical sized calvarial defects were created in our study. ${ }^{20-23}$ Furthermore, in the control group, the healing was characterized with the collagen fibers and high amounts of fibroblasts in the connective tissue. Bone formation was observed only in the edges of defect.

By using bone grafting in the bone defects, the expected healing was to see regeneration and new bone formation. ${ }^{24}$ However, in previous studies, it has been reported that FDBA and DFDBA type allograft were observed in new periodontal ligament, cement and alveolar bone formation as a percentage of $50-60 \%$ and $80 \%$, respectively. ${ }^{25-28}$ Also, several studies suggested that allograft (Puros ${ }^{\circledR}$ ) was superior than the other graft materials, and that it was almost as effective as autogenous graft. ${ }^{29-31}$

Ozone can be applied in different ways such as gaseous, oil or water. In our study, we used the ozone generator that produced gaseous ozone. Gaseous ozone application did not cause any side effects in rats. However, there are many ozone generators on the market while there was no protocol recommendations for bone healing or bone regeneration. Also, the amount of ozone produced by these devices are different. In animal studies performed with ozone devices have been obtained different results.

While ozone gas is preferred as an antibacterial agent in dentistry, it also has properties of activating the blood components (erythrocytes, leucocytes, platelets, endothelial cells), and this may have an important role in healing wounds due to its positive effect on key processes such as microcirculation, antioxidant defense system, oxygen metabolism. ${ }^{32}$ Nogales et al. ${ }^{33}$ showed that ozone application must be included in the dentistry practice, and that it could even be an alternative to antibiotic treatment in alveolitis treatment. 
Low level laser, hyperbaric oxygen, platelet rich plasma and platelet rich fibrin and other treatment regimens were tried in order to increase of the bone graft healing in the literature and different results were reported. The effects of ozone on bone healing have been histologically examined in recent studies. ${ }^{34-36}$ Kazancioğlu et al. demonstrated that both ozone and laser therapies had a positive effect on bone formation in rat calvarial defect compared with the control group; also, ozone therapy was more effective than low level laser treatment. ${ }^{35}$ Another study by the same authors ${ }^{36}$ suggested that ozone therapy was useful for the reduction of postoperative pain and increased quality of life after third molar surgery. However, it had no effect on postoperative swelling or trismus. In our study, ozone increased osteoblast numbers and total bone area in allograft+ozone group comparing to allograft group at 8 th weeks.

In addition to the studies that dealt with the beneficial effects of ozone, there are also reports of adverse reactions associated with its use. ${ }^{37}$ Bocci et al. ${ }^{38}$ reported that long term inhalation of ozone induced to health problems while low-dose ozone could be calibrated well and showed positive effects and triggered the antioxidant capacity of the blood .

\section{CONCLUSION}

Within the limitations of the present study, it was concluded that the ozone therapy increased bone formation with allograft in rat calvarial defect model. This study is a first in terms of results and analyzed studies related to ozone and allograft. However, additional studies are required to clarify the effects of different ozone applications on new bone formation.

\section{Acknowledgement}

This study was supported by the Cumhuriyet University Unit of Scientific Research Projects with a project number DIS-133.

\section{REFERENCES}

1. Jensen SS, Broggini N, HjortingHansen H, Schenk R, Buser D. Bone healing and graft resorption of autograft, anorganic bovine bone and beta-tricalcium phosphate. A histologic and histomorphometric study in the mandibles of minipigs. Clin Oral Implants Res 2006; 17(3): 237-43.

2. Oh KC, Cha JK, Kim CS, Choi SH, Chai JK, Jung UW. The influence of perforating the autogenous block bone and the recipient bed in dogs. Part I: a radiographic analysis. Clin Oral Implants Res 2011; 22(11): 1298-302.

3. Reynolds MA, Bowers GM. Fate of demineralized freeze-dried bone allografts in human intrabony defects. J Periodontol 1996; 67(2): 150-157.

4. Salyer KE, Bardach J, Squier CA, Gendler E, Kelly M. Cranioplasty in the growing canine skull using demineralized perforated bone. Plast Reconstr Surg; 1995: 96(4):. 770779 .

5. Paper, A.A.P.P., Tissue Banking Of Bone Allografts Used in Periodontal Regeneration. J Periodontol 2001;72: 834-838.

6. Shigeyama Y, D'Errico JA, Stone R, Somerman MJ. Commerciallyprepared allograft material has 
biological activity in vitro. J Periodontol 1995; 66(6): 478-487.

7. Messora MR, Nagata MJ, Fucini SE, Pola NM, Campos N, de Oliveira GC et. al. Effect of platelet-rich plasma on the healing of mandibular defects treated with fresh frozen bone allograft: a radiographic study in dogs. J Oral Implantol 2014; 40(5): 533-541.

8. The potential role of growth and differentiation factors in periodontal regeneration. J Periodontol, 1996;67(5): 545-553.

9. Fideler BM, Moore T, Li Z, Rasheed $S$. Effects of gamma irradiation on the human immunodeficiency virus. A study in frozen human bonepatellar ligament-bone grafts obtained from infected cadavera. J Bone Joint Surg Am 1994;76-A(7): 1032-1035.

10. Cornu O, Libouton $X$, Naets $B$, Godts B, Van Tomme J, Delloye C, et. a. Freeze-dried irradiated bone brittleness improves compactness in an impaction bone grafting model. Acta Orthop Scand 2004; 75(3): 309314.

11. Garrett S. Periodontal regeneration around natural teeth. Ann Periodontol 1996; 1(1): 621-666.

12. Babbush CA. The use of a new allograft material for osseous reconstruction associated with dental implants. Implant Dent 1998; 7(3): 205-212.

13. Babbush CA. Histologic evaluation of human biopsies after dental augmentation with a demineralized bone matrix putty. Implant Dent 2003; 12(4): 325-332.
14. Guerra OC, C.S., Jordan MEM, Vazquez and TC,. Aplicación de la ozonoterapia en el tratamiento de la alveolitis. Revista Cubana de Estomatologia 1995; 34: 21-24.

15. Petrucci MT, Gallucci C, Agrillo A, Mustazza MC, Foa R. Role of ozone therapy in the treatment of osteonecrosis of the jaws in multiple myeloma patients. Haematologica 2007; 92(9): 1289-1290.

16. Ozdemir H, Toker H, Balci H, Ozer H. Effect of ozone therapy on autogenous bone graft healing in calvarial defects: a histologic and histometric study in rats. J Periodontal Res 2013; 48(6): 722726.

17. Frame JW. A convenient animal model for testing bone substitute materials. J Oral Surg 1980;38(3): 176-180.

18. Bays RA. The influence of systemic bone disease on bone resorption following mandibular augmentation. Oral Surg Oral Med Oral Pathol 1983; 55(3): 223-231.

19. Higuchi $T$, Kinoshita A, Takahashi $\mathrm{K}$, Oda S, Ishikawa I. Bone regeneration by recombinant human bone morphogenetic protein-2 in rat mandibular defects. An experimental model of defect filling. J Periodontol 1999; 70(9): 1026-1031.

20. Dupoirieux L, Pourquier D, Picot MC, Neves M. Comparative study of three different membranes for guided bone regeneration of rat cranial defects. Int J Oral Maxillofac Surg 2001; 30(1): 58-62.

21. Ivanovski S, Hamlet $S$, Retzepi $M$, Wall I, Donos N. Transcriptional profiling of "guided bone 
regeneration" in a critical-size calvarial defect. Clin Oral Implants Res 2011; 22(4): 382-389.

22. Kochi G, Sato S, Fukuyama $T$, Morita C, Honda K, Arai Y, et. al. Analysis on the guided bone augmentation in the rat calvarium using a microfocus computerized tomography analysis. Oral Surg Oral Med Oral Pathol Oral Radiol Endod 2009; 107(6): e42-48.

23. Notodihardjo FZ, Kakudo N, Kushida S, Suzuki K, Kusumoto K. Bone regeneration with BMP-2 and hydroxyapatite in critical-size calvarial defects in rats. $J$ Craniomaxillofac Surg 2012; 40(3): 287-291.

24. Ellegaard B. Bone grafts in periodontal attachment procedures. $\mathrm{J}$ Clin Periodontol 1976; 3(5): 1-54.

25. Mellonig JT, Bowers GM, Bright RW, Lawrence JJ. Clinical evaluation of freeze-dried bone allografts in periodontal osseous defects. J Periodontol 1976; 47(3): 125-131.

26. Galgut PN, Waite IM, Brookshaw JD, Kingston CP. A 4-year controlled clinical study into the use of a ceramic hydroxylapatite implant material for the treatment of periodontal bone defects. J Clin Periodontol 1992; 19(8): p. 570-7.

27. Dragoo MR, Sullivan HC. A clinical and histological evaluation of autogenous iliac bone grafts in humans. I. Wound healing 2 to 8 months. J Periodontol, 1973; 44(10): 599-613.

28. Reynolds MA, Aichelmann-Reidy ME, Branch-Mays GL, Gunsolley JC. The efficacy of bone replacement grafts in the treatment of periodontal osseous defects. A systematic review. Ann Periodontol 2003; 8(1): 227-265.

29. Schmitt CM, Doering H, Schmidt $T$, Lutz R, Neukam FW, Schlegel KA, Histological results after maxillary sinus augmentation with Straumann(R) BoneCeramic, BioOss(R), Puros(R), and autologous bone. A randomized controlled clinical trial. Clin Oral Implants Res 2013; 24(5): 576-585.

30. Froum SJ, Wallace SS, Elian N, Cho SC, Tarnow DP. Comparison of mineralized cancellous bone allograft (Puros) and anorganic bovine bone matrix (Bio-Oss) for sinus augmentation: histomorphometry at 26 to 32 weeks after grafting. Int $\mathbf{J}$ Periodontics Restorative Dent 2006; 26(6): 543-551.

31. Noumbissi SS, Lozada JL, Boyne PJ, Rohrer MD, Clem D, Kim JS, et.al. Clinical, histologic, and histomorphometric evaluation of mineralized solvent-dehydrated bone allograf (Puros) in human maxillary sinus grafts. J Oral Implantol 2005; 31(4): 171-179.

32. Mollica P, H.R. Integrating oxygen/ ozone therapy into your practice. 2010 Available from: http://www. Toxin free smile. Dom/ images/ozone integrating $\% 20$ oxygen ozone.

33. Trombelli L1, Heitz-Mayfield LJ, Needleman I, Moles D, Scabbia A. A systematic review of graft materials and biological agents for periodontal intraosseous defects. J Clin Periodontol 2002;29: Suppl 3:11735. 
Toker, et al.: The Effects Of Allograft Combined With Ozone Therapy On Regeneration Of Calvarial Defects In Rats

34. Kang YH, Jeon SH, Park JY, Chung JH, Choung YH, Choung HW, et. al. Platelet-rich fibrin is a Bioscaffold and reservoir of growth factors for tissue regeneration. Tissue Eng Part A 2011; 17: 349-359.

35. Kazancioglu HO, Ezirganli S, Aydin MS. Effects of laser and ozone therapies on bone healing in the calvarial defects. J Craniofac Surg 2013; 24(6): 2141-2146.

36. Kazancioglu HO, Kurklu E, Ezirganli S. Effects of ozone therapy on pain, swelling, and trismus following third molar surgery. Int $\mathrm{J}$
Oral Maxillofac Surg 2014; 43(5): 644-648.

37. Stubinger S, Sader R, Filippi A. The use of ozone in dentistry and maxillofacial surgery: a review. Quintessence Int 2006; 37(5): 353359.

38. Bocci V, Valacchi G, Corradeschi C, Aldinucci C, Silvestri S, Paccagnini E et al. Studies on the biological effects of ozone: 7. Generation of reactive oxygen species (ROS) after exposure of human blood to ozone. $\mathbf{J}$ Biol Regul Homeost Agents 1998; 12(3): 67-75. 